\title{
SPARK PLASMA SINTERING OF GRAPHENE REINFORCED SILICON CARBIDE CERAMICS
}

\author{
Eszter Bódis ${ }^{1}$, Ildikó Cora ${ }^{2}$, Csaba Balázsi ${ }^{2}$, Péter Németh ${ }^{1}$, Zoltán Károly ${ }^{1}$, Szilvia Klébert ${ }^{1}$, \\ Péter Fazekas ${ }^{1}$, Anna M. Keszler ${ }^{1}$, János Szépvölgyi ${ }^{1}$ \\ ${ }^{1}$ Plasma Chemistry Research Group, Institute of Materials and Environmental Chemistry, Research \\ Center for Natural Sciences, Hungarian Academy of Sciences, Budapest, Hungary \\ ${ }^{2}$ Thin Film Physics Department, Institute of Technical Physics and Materials Science, Centre for Energy \\ Research, Hungarian Academy of Sciences, Budapest, Hungary \\ Corresponding author: bodis.eszter@ttk.mta.hu
}

\begin{abstract}
Silicon carbide ( $\mathrm{SiC}$ ) ceramics have superior properties in terms of wear, corrosion, oxidation, thermal shock resistance and high temperature mechanical behavior, as well. However, they can be sintered with difficulties and have poor fracture toughness, which hinder their widespread industrial applications. In this work, SiC-based ceramics mixed with $1 \mathrm{wt} \%$ and 3 wt $\%$ multilayer graphene (MLG), respectively, were fabricated by solid-state spark plasma sintering (SPS) at different temperatures. We report the processing of MLG/SiC composites, study their microstructure and mechanical properties and demonstrate the influence of MLG loading on the microstructure of sintered bodies. It was found that MLG improved the mechanical properties of SiC-based composites due to formation of special microstructure. Some toughening mechanism due to MLG pull-out and crack bridging of particles was also observed. Addition of $3 \mathrm{wt} \%$ MLG to SiC matrix increased the Vickers hardness and Young's modulus of composite, even at a sintering temperature of $1700^{\circ} \mathrm{C}$. Furthermore, the fracture toughness increased by $20 \%$ for the $1 \mathrm{wt} \%$ MLG-containing composite as compared to the monolithic SiC selected for reference material. We demonstrated that the evolved $4 \mathrm{H}-\mathrm{SiC}$ grains, as well as the strong interactions among the grains in the porous free matrices played an important role in the mechanical properties of sintered composite ceramics.
\end{abstract}

Keywords: spark plasma sintering (SPS), SiC, multilayer graphene (MLG), mechanical properties 


\section{Introduction}

Silicon carbide $(\mathrm{SiC})$ is an advanced engineering ceramic with a range of excellent characteristics, such as good mechanical properties both at low and high temperatures, high resistance to corrosion and oxidation, good thermal and chemical stability, as well as unique electrical properties. By all these properties $\mathrm{SiC}$ candidates for broad industrial application, especially in fabricating aero-engines [1]. The more versatile application of SiC ceramics, however, is impeded by their most critical mechanical property, i.e. the poor fracture toughness. Another problem associated with bulk SiC ceramics is that they can be sintered with difficulties. Green bodies of pure $\mathrm{SiC}$ can be sintered only above $2200^{\circ} \mathrm{C}$ for a dense microstructure, because of the strong covalent $\mathrm{Si}-\mathrm{C}$ bonds and the low self-diffusion coefficient of $\mathrm{SiC}$. In order to achieve high final densities at temperature below $2000^{\circ} \mathrm{C}$, liquid-phase sintering (LPS) is commonly applied in the presence of oxide-based sintering additives. Lee at al. [2] reported that liquid forming additives greatly promote the densification of $\mathrm{SiC}$, however, they are also responsible for the degradation of mechanical properties at high-temperatures since the glassy phase solidifying at the boundaries of $\mathrm{SiC}$ grains becomes soft at higher temperature. Maître et al. [3] also studied the effect of sintering additives on LPS of SiC ceramics, and they have found a lower corrosion resistance in the secondary glassy phases than in the SiC matrix. Can et al. [4] published that the liquid-forming oxide additives could react with the silicon carbide on sintering. Shinoda et al. [5] described similar reactions for $\mathrm{SiC}$ densified in the presence of $\mathrm{Al}_{2} \mathrm{O}_{3}$ and $\mathrm{TiO}_{2}$ to form $\mathrm{TiC}$ by the reaction of $\mathrm{TiO}_{2}$ and $\mathrm{SiC}$.

Solid-state sintering in the presence of boron and carbon as solid sintering aids is also viable to obtain high final density. Boron and carbon reduce the surface energy of $\mathrm{SiC}$ grains and thus, dense ceramic bodies can be obtained even at around $2000^{\circ} \mathrm{C}[6,7]$. In addition, during solidstate sintering formation of intergranular phases, and consequently, the decrease of corrosion resistance can be avoided.

In recent years, plenty of efforts have been devoted to improve the mechanical properties, especially the fracture toughness of SiC. Song et al. [8] studied the effects of $\mathrm{SiC}$ whiskers on the mechanical properties and microstructure of SiC ceramics. A maximum fracture toughness of 5.6 $\mathrm{MPa} \cdot \mathrm{m}^{1 / 2}$ was reached with integration of pre-coated $\mathrm{SiC}$ whiskers in $15 \mathrm{wt} \%$. In contrast, a lower value of 3.4 $\mathrm{MPa}^{1 / 2}$ was obtained using as-received, uncoated SiC whiskers. Wilhelm et al. [9] tried to improve the fracture toughness of $\mathrm{SiC}$ composites by adding silicon powder. However, they couldn't improve the fracture toughness, which remained constant $\left(\sim 3.8 \mathrm{MPa} \cdot \mathrm{m}^{1 / 2}\right)$ in all samples. Padture [10] demonstrated an in-situ toughening of $\mathrm{SiC}$ by employing post heat treatment after sintering that induced the formation of large elongated or platelet-shaped grains. The appearance of such grain structures was based on the $\beta \rightarrow \alpha$-SiC transition occurring at $1800-2000^{\circ} \mathrm{C}$. In this way, some improvement of fracture toughness $\left(\mathrm{K}_{\mathrm{IC}}\right)$ to $5.5 \mathrm{MPa} \cdot \mathrm{m}^{1 / 2}$ was achieved. Kovalcíková et al. [11] - besides adding $\mathrm{Si}_{3} \mathrm{~N}_{4}$ as reinforcing phase -, also investigated 
the post heat treatment of SiC-based ceramics fabricated by LPS. They found no evidence for the influence of $\mathrm{Si}_{3} \mathrm{~N}_{4}$ addition on the indentation toughness of the sintered $\mathrm{SiC}$, nevertheless, after post heat treatment the microstructure of the composites significantly changed due to $\beta \rightarrow \alpha-\mathrm{SiC}$ transition, and it led to the increase of $\mathrm{K}_{\mathrm{IC}}$ to a value of $\sim 5.4 \mathrm{MPa} \cdot \mathrm{m}^{1 / 2}$.

In the last decade graphene received widespread attention due to its extraordinary properties and versatile potential applications. Numerous studies have demonstrated that addition of graphene to polymers [12], metals and ceramics [13-15] significantly improved the charge transport, the thermal and optical properties of composites, even at relatively low graphene content [16-19]. It has been also claimed that graphene could be a promising additive to advanced composite material due to its high tensile strength and Young's modulus [20]. Graphene has attracted a great interest as an efficient toughening additive to oxide and non-oxide ceramics, as well [20-25]. Porwal et al. [26] published an extensive review on the state-of-art of grapheneceramics composites. We found previously that the fracture toughness of $\mathrm{Si}_{3} \mathrm{~N}_{4}$ ceramic had been improved by $60 \%$ by adding $1 \mathrm{wt} \%$ MLG to the matrix. However, the increase of graphene content above $3 \mathrm{wt} \%$ made the sintered ceramics more porous and led to inferior mechanical properties [27].

Up to now only a few papers have been published on silicon carbide ceramics reinforced with graphene nano-platelets. Miranzo et al. [28] investigated manufacturing of SiC/graphene composites with additives for liquid phase sintering. In their study the graphene sheets $(\sim 4 \mathrm{vol} \%)$ grew in-situ in the bulk SiC ceramics during SPS. The in-situ formed graphene improved the fracture toughness of the dense $\mathrm{SiC}$ ceramics by $\sim 55 \%$. Belmonte et al. [29] also studied the improvement of the mechanical properties of $\mathrm{SiC}$ during liquid-phase spark plasma sintering in the presence of different graphene additives, namely graphene nano- platelets (GNP) and reduced graphene oxide (rGO). Addition of 5 vol\% rGOs to the $\mathrm{SiC}$ matrix improved $\mathrm{K}_{\mathrm{IC}}$ by $162 \%$ (to 8.3 $\left.\mathrm{MPa} \cdot \mathrm{m}^{1 / 2}\right)$ at a strength of $600 \mathrm{MPa}$. For the GNP additive (10 vol\% graphene content) the fracture toughness increased to $5.9 \mathrm{MPa} \cdot \mathrm{m}^{1 / 2}$, while the strength remained constant at around 600 $\mathrm{MPa}$. Li et al. [30] studied the pressure-less sintering of $\mathrm{SiC}$. The highest fracture toughness of $5.65 \mathrm{MPa} \cdot \mathrm{m}^{1 / 2}$ was obtained for a sample with $1.0 \mathrm{wt} \%$ graphene content by solid-state sintering at $2130^{\circ} \mathrm{C}$, for $1 \mathrm{~h}$ in $\mathrm{Ar}$ atmosphere. The above fracture toughness was higher by $22 \%$ as compared to $\mathrm{SiC}$ ceramics without graphene.

In this work we studied the solid-state spark plasma sintering of SiC/multilayer graphene (MLG) composites. Our research aimed at better understanding of the toughening mechanism of graphene, the phenomena occurring at the grain boundaries between SiC and MLG, as well as correlation between the evolved microstructure and the mechanical properties.

\section{Material and methods}

The matrix material consisted of $97 \mathrm{wt} \% \alpha-\mathrm{SiC}$ powder (Washington Mills, 1-3 $\mu \mathrm{m}$ particle size) and $3 \mathrm{wt} \%$ boron powder (H.C. Starck, Germany) as solid-state sintering aid. MLG was added to the mixtures in 1 and $3 \mathrm{wt} \%$, respectively. MLG was prepared by mechanical milling 
[31], and its average thickness was 15-20 nm. To avoid agglomeration of the graphene layers we dispersed the milled MLG in absolute ethanol (VWR International) by ultrasonic mixing for 30 mins. The next step was the mixing of the SiC-boron powder with the MLG dispersion in ethanol for $90 \mathrm{~min}$, followed by drying at $90^{\circ} \mathrm{C}$. A graphene-free silicon carbide-boron mixture was also prepared for reference using the same process as above. The dry powder mixtures were further homogenized in a Frisch mill (Pulverisette 6) at $300 \mathrm{rpm}$ for $60 \mathrm{~min}$.

Spark plasma sintering was carried out in a HD P5 equipment (FCT GmbH) at four different sintering temperatures $\left(1700^{\circ} \mathrm{C}, 1750^{\circ} \mathrm{C}, 1800^{\circ} \mathrm{C}\right.$ and $1850^{\circ} \mathrm{C}$, respectively). The powders were heated by a rate of $100^{\circ} \mathrm{C} \cdot \mathrm{min}^{-1}$ using on/off current pulses of $12 / 2 \mathrm{~ms}, 3500 \mathrm{~A}$ and $5 \mathrm{~V}$. The holding time at the maximum temperature was $5 \mathrm{~min}$. During sintering uniaxial pressing of 50 $\mathrm{MPa}$ and a chamber pressure of 1 mbar were maintained. The applied heating current and voltage were monitored and recorded along with the shrinkage of the powder and displacement.

The density of sintered samples was measured by Archimedes method. Their morphology and microstructure were studied by a Zeiss EVO40 scanning electron microscope (SEM), a Philips CM20 and a JEOL JEM 3010 transmission electron microscope (TEM), respectively. The phase compositions of the sintered samples were determined by a Philips PW 1830 X-ray diffractometer (XRD). The Raman spectra of the initial mixture of $\mathrm{SiC}$ with $3 \mathrm{wt} \% \mathrm{MLG}$ powder and the sintered $\mathrm{SiC} / 3 \mathrm{wt} \%$ MLG composites were registered in the Raman shift range of 200$3000 \mathrm{~cm}^{-1}$ by a Horiba Jobin-Yvon HE532 Raman spectrometer equipped with a Nd:YAG laser $(532 \mathrm{~nm})$. The mechanical properties of sintered samples were characterized by measuring their hardness and Young's modulus, using the CSM2008 instrumented indentation method (9,807 N Vickers diamond indentation force for $10 \mathrm{sec}$.). During measurement the applied load and indenter's displacement were recorded both on loading and unloading. The Vickers hardness and Young's modulus were calculated by the Oliver and Pharr method [32]. The indentation fracture toughness was calculated from the measured data by the Niihara equation [33]. Numerous comparative studies [34-35] have confirmed that the $\mathrm{K}_{\mathrm{IC}}$ values calculated by the Niihara equation were in good agreement with the conventional (Chevron notched beam, SEVNB) testing method of fracture toughness. It is also an important issue that the cracks created by the Vickers indenter could be used for studying the possible toughening mechanisms during crack propagation under load for determination of $\mathrm{K}_{\mathrm{IC}}[14,26,36]$.

\section{Results and discussion}

\subsection{Density}

The relative densities of different $\mathrm{SiC} / \mathrm{MLG}$ samples were plotted against the sintering temperature in Fig. 1. The measured and calculated theoretical densities of samples with $3 \mathrm{wt} \%$ graphene addition were almost identical at sintering temperature of $1700^{\circ} \mathrm{C}$. There was a steep rise in the density between 1700 and $1800^{\circ} \mathrm{C}$ for samples with 0 and $1 \mathrm{wt} \%$ graphene content. The increase of graphene content resulted in higher relative densities at all sintering temperatures. It was also remarkable that the solid-state sintering of samples containing $3 \mathrm{wt} \% \mathrm{MLG}$ resulted in 
relative densities over $99 \%$ above $1700^{\circ} \mathrm{C}$. Hence, addition of MLG and application of the SPS proved to be effective tools in achieving high relative densities in particular system.

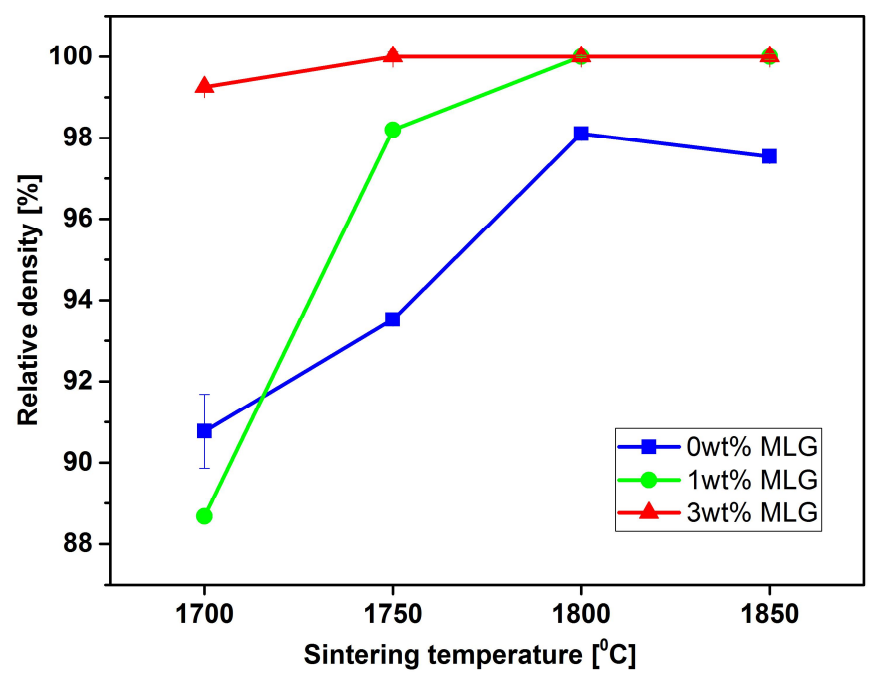

Fig. 1. Relative densities of sintered samples against the sintering temperature

The apparently favorable effect of graphene addition on the relative densities can be attributed to the unique properties of graphene. Graphene has higher electrical conductivity and also better thermal conductivity, $\left(10^{6} \Omega^{-1} \cdot \mathrm{cm}^{-1}\right.$ and $\left.5300 \mathrm{~W} \cdot \mathrm{m}^{-1} \cdot \mathrm{K}^{-1}\right)$ than $\mathrm{SiC}\left(\sim 10^{4} \Omega^{-1} \cdot \mathrm{cm}^{-1}\right.$ and $\left.\sim 120 \mathrm{~W} \cdot \mathrm{m}^{-1} \cdot \mathrm{K}^{-1}\right)$. Thus, the pulsed current and the heat are more effectively and more uniformly distributed within the graphene containing samples during sintering than without graphene. As a result, higher relative densities can be achieved in the presence of graphene. This phenomenon is especially supported by comparing the relative densities of samples containing 0 and $3 \mathrm{wt} \%$ graphene, sintered at $1700^{\circ} \mathrm{C}$. In the former case the relative density was $89 \%$, while in the latter one it was $98.1 \%$. Nieto et al. [37] reported similar correlation between the graphene content and the relative density for the TaC/graphene system. However, Pereira dos Santos Tonello et al. [38] found that over 4 vol\% graphene content an interconnected graphene network were formed that hindered densification and resulted in lower relative densities.

We suggest that MLG addition significantly promotes shrinkage during sintering due to improved heat transfer conditions. Fig. 2. shows the sintering process started at $1600^{\circ} \mathrm{C}$ for all samples. However, at higher MLG contents higher shrinkage were recorded at the maximum temperature of sintering. 


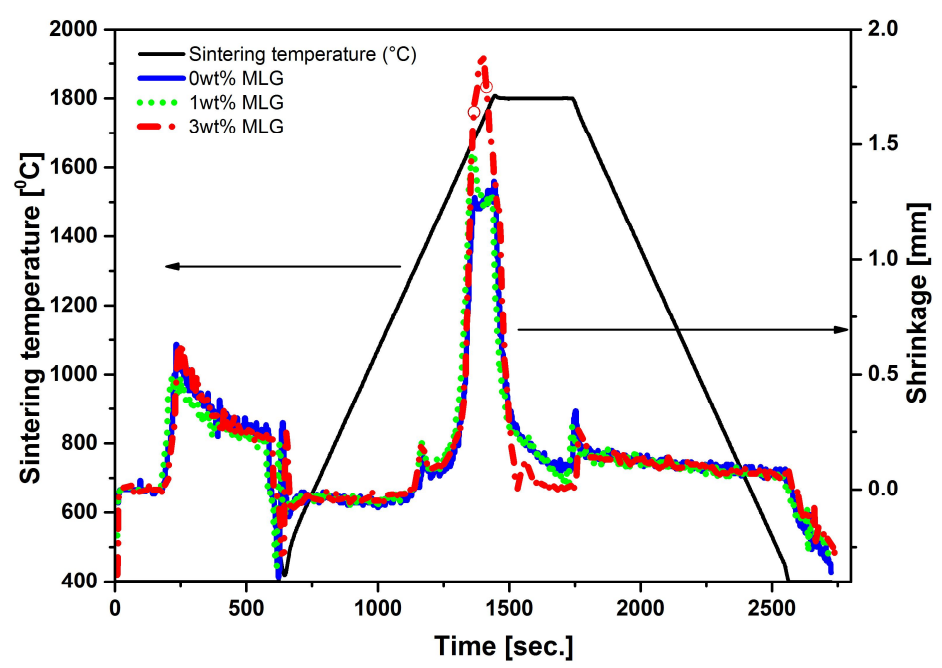

Fig. 2. Temperature and shrinkage profiles during SPS of SiC/MLG composites

\subsection{Structure}

The $\alpha$-SiC exhibits large number of polytype structures with different stacking sequences of the Si-C bilayers. The two most important hexagonal polytypes are $6 \mathrm{H}-\mathrm{SiC}$ and $4 \mathrm{H}-\mathrm{SiC}$. In this work both polytypes were observed in the starting $\alpha$-SiC powder by XRD. During SPS the $6 \mathrm{H}-$ $\mathrm{SiC}$ polytype was transformed to $4 \mathrm{H}-\mathrm{SiC}$ (Fig. 3.) and the ratio of transformed $4 \mathrm{H}$ polytype increased with sintering temperature. The initial $4 \mathrm{H}-\mathrm{SiC}$ content of $7 \%$ was increased to $60 \%$ during sintering at $1850^{\circ} \mathrm{C}$. Similar results have been reported by Tanaka et al. in [6]: boron promoted the formation of $4 \mathrm{H}$ polytype with plate-like structure, which resulted in stacking faults and enhanced the rate of the polymorph transformation of SiC.

The crystallite sizes of the initial and sintered SiC, respectively, were determined by the Scherrer-equation from the XRD results. The initial powder had an average crystallite size of $\sim 190 \mathrm{~nm}$ that grew over $1 \mu \mathrm{m}$ after sintering at $1850^{\circ} \mathrm{C}$. 


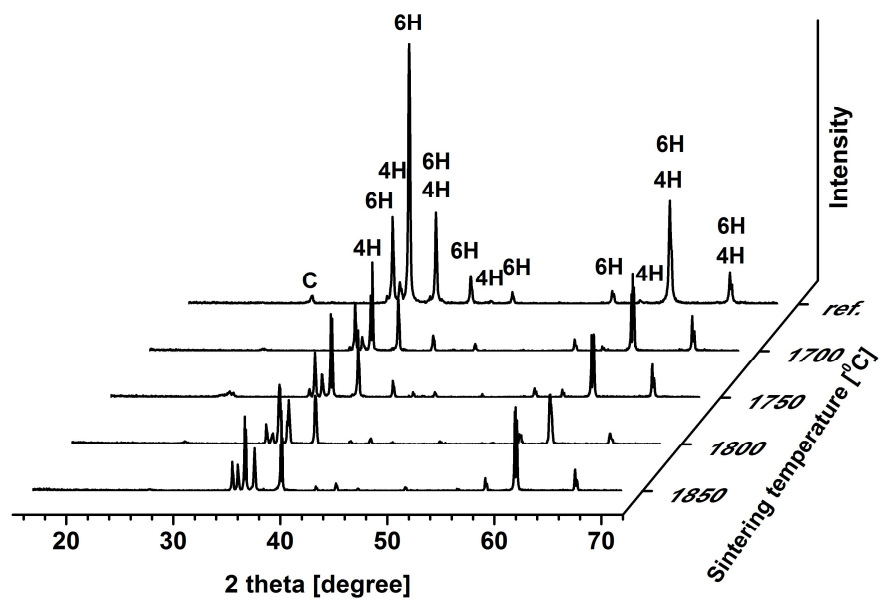

Fig. 3. XRD patterns of the initial SiC powder and the sintered $\mathrm{SiC} / 3 \mathrm{wt} \% \mathrm{MLG}$ composites

We studied the fracture surface of sintered samples by SEM in order to gain information on the correlation between the microstructure, the sintering conditions and the distribution of graphene sheets in the matrix. The starting $\mathrm{SiC}$ powder exhibited a relatively fine microstructure with a mean particle size of 3-4 $\mu \mathrm{m}$ and crystallite size of $\sim 190 \mathrm{~nm}$. During SPS of pure SiC at $1700^{\circ} \mathrm{C}$ the grain size increased to $10-15 \mu \mathrm{m}$. We detected many residual pores in the matrix (Fig. 4 a). However, the neck formation among the grains was also observed indicating the initial stage of sintering. In contrast, in the sample sintered at $1850^{\circ} \mathrm{C}$ larger grains and much denser microstructure were developed (Fig. 4 b). The added boron could be incorporated in the structure of $\mathrm{SiC}$, stabilized the $4 \mathrm{H}$ polytype and led to the formation of stacking faults, creating anisotropy in the crystals. As a result, elongated and plate-like grains were developed, that could greatly influence the fracture toughness of $\mathrm{SiC}$, similarly to $\mathrm{Si}_{3} \mathrm{~N}_{4}[39-40]$.
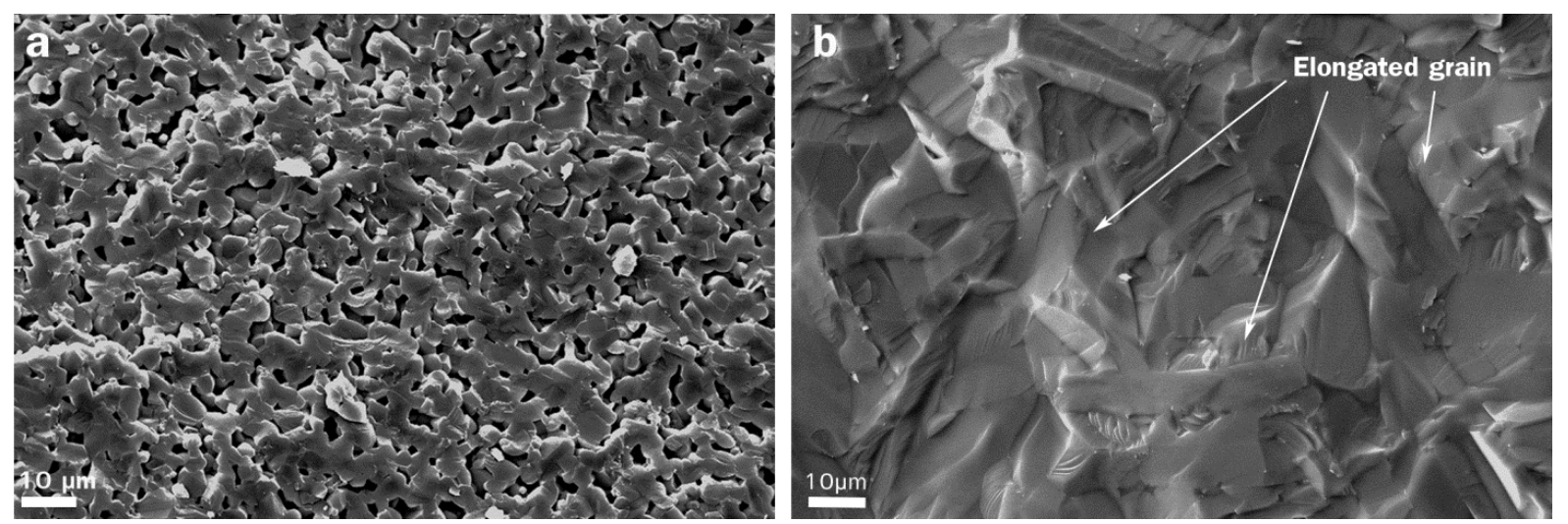

Fig. 4. SEM micrographs of the fracture surface of SiC $/ 0 \mathrm{wt} \% \mathrm{MLG}$ sintered at $1700^{\circ} \mathrm{C}$ (a) and the fracture surface of $\mathrm{SiC} / 1 \mathrm{wt} \% \mathrm{MLG}$ sintered at $1850^{\circ} \mathrm{C}(\mathrm{b})$ 
Owing to the applied preparation method of composite powder, MLG was pretty uniformly distributed in the SiC-B matrix (Fig. 5.). In most samples MLG was well oriented, due to the uniaxial sintering pressure (Fig. 5 c). At lower graphene content ( $\mathrm{SiC} / 1 \mathrm{wt} \% \mathrm{MLG}$ ) the graphene platelets were well separated and dispersed in the matrix and MLG could be observed at higher magnifications only (Fig. 5 a, b). At higher graphene content (SiC/3wt\% MLG), the graphene platelets might overlap and formed agglomerates in the matrix (Fig. $5 \mathrm{~d}$ ).
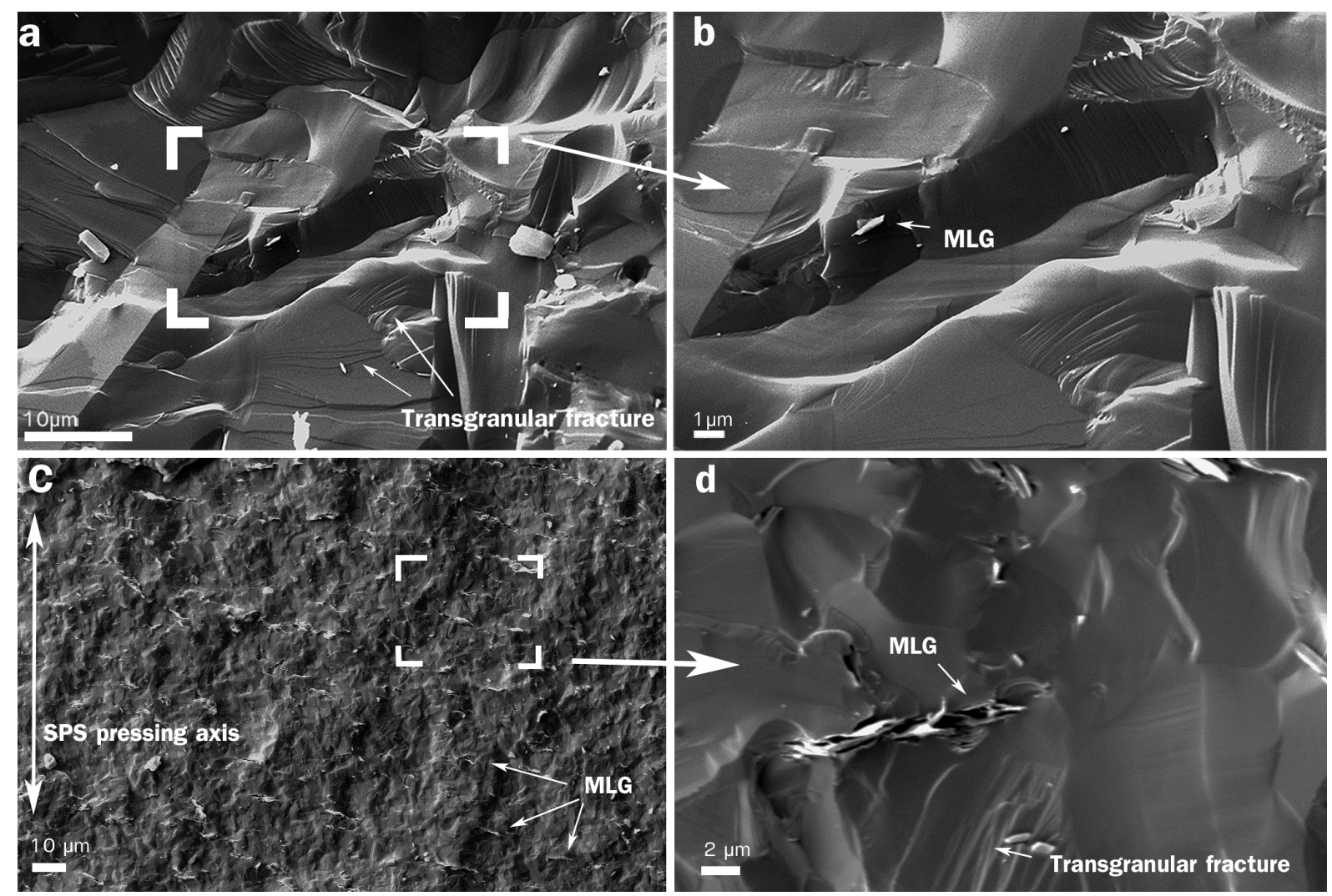

Fig. 5. SEM micrographs of the cross section of fractured surfaces of the samples $\mathrm{SiC} / 1 \mathrm{wt} \%$ MLG (a, b) and SiC $/ 3 \mathrm{wt} \%$ MLG (c, d) sintered at $1800^{\circ} \mathrm{C}$

Furthermore, we observed some typical toughening effects, such as pull-out of graphene sheets and crack bridging (Fig. 6 a and b). We also detected trans-granular fractures in all samples. 

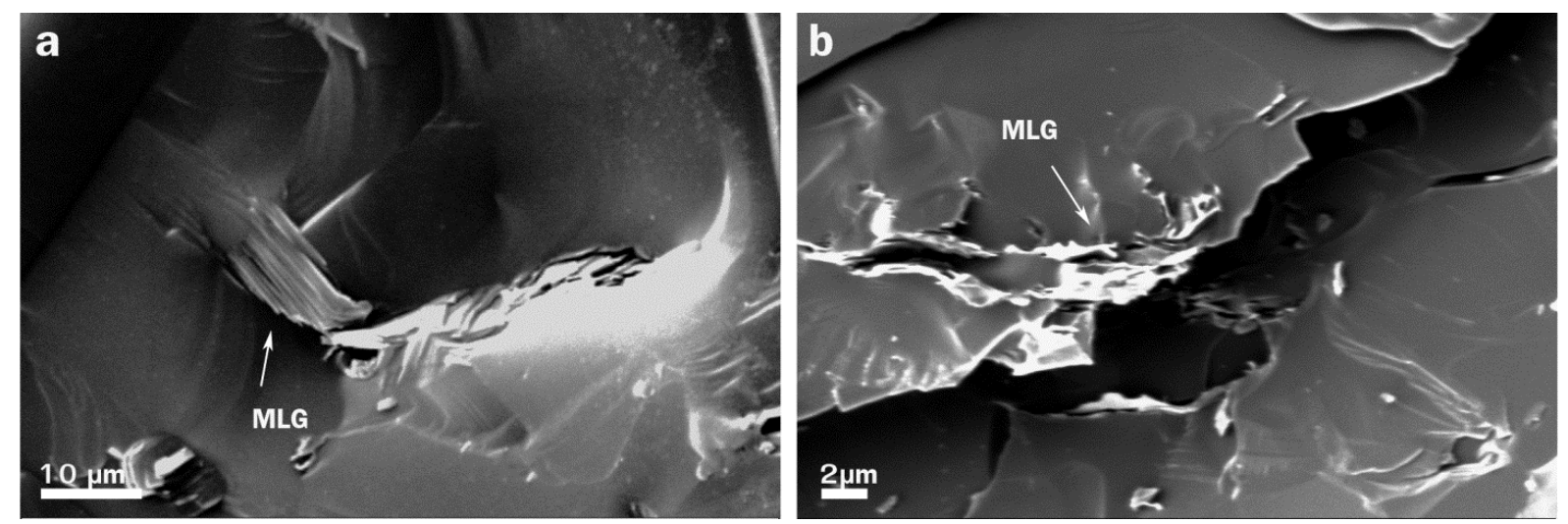

Fig. 6. Toughening mechanisms in sintered $\mathrm{SiC} / 3 \mathrm{wt} \% \mathrm{MLG}$ composite: (a) MLG nano-sheet pull-out and (b) crack bridging

It is known that the interface between graphene and $\mathrm{SiC}$ plays an important role in the mechanical properties of SiC/graphene composites. For better understanding the role of MLG and its interface in SiC-based composites, we investigated the microstructure of our samples by TEM, as well.

In the sample, which did not contain MLG and was subjected to SPS at $1850^{\circ} \mathrm{C}$, we detected the thermodynamically unstable cubic (3C) $\mathrm{SiC}$ [6] beside the hexagonal polymorph (Fig. 7.). The $6 \mathrm{H}-\mathrm{SiC}$ grain was partially transformed into $4 \mathrm{H}-\mathrm{SiC}$ and included numerous stacking faults (see white arrows pointing to grey strips in Fig. 7.). The stacking faults could facilitate the $6 \mathrm{H} \rightarrow$ $4 \mathrm{H}$ transformation and it might induce the hexagonal $\rightarrow$ cubic transformation, as well.

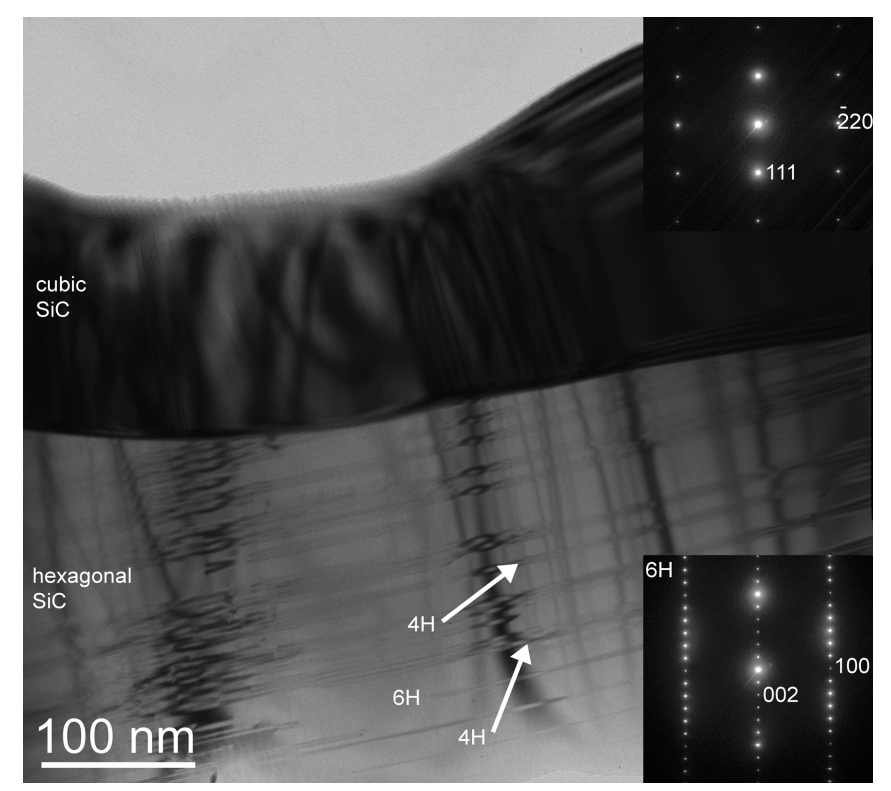

Fig. 7. HR-TEM micrograph of $\mathrm{SiC} / 0 \mathrm{wt} \% \mathrm{MLG}$ sample sintered at $1850^{\circ} \mathrm{C}$ 
TEM images also showed that the agglomerated graphene formed graphite (Fig. 8.) in samples with $3 \mathrm{wt} \%$ MLG content, as the results of high sintering temperature and uniaxial pressure. In addition, at the grain boundaries between graphite and $\mathrm{SiC}$ a boron carbide intergranular phase was developed, which we attributed to the $\mathrm{B}_{4} \mathrm{C}$ polymorph (PDF2\#35-0798). This material likely formed above $1800^{\circ} \mathrm{C}$ in a reaction between boron and graphene. $\mathrm{B}_{4} \mathrm{C}$ had an average thickness of $100 \mathrm{~nm}$ and surrounded the graphite particle. The TEM image confirmed that $\mathrm{SiC}$, graphite and $\mathrm{B}_{4} \mathrm{C}$ were well-sintered together and were strongly bonded. These observations were in agreement with SEM investigations, which showed trans-granular rather than inter-granular fractures.

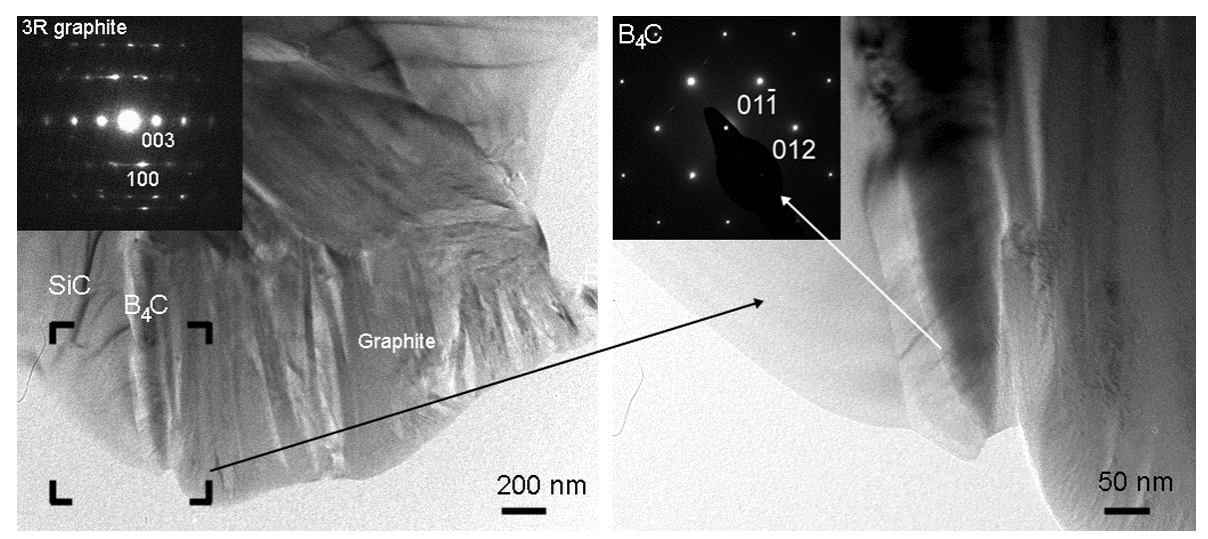

Fig. 8. HR-TEM micrograph of $\mathrm{SiC} / 3 \mathrm{wt} \% \mathrm{MLG}$ sintered at $1850^{\circ} \mathrm{C}$

The Raman spectra recorded for studying the structure of MLG during SPS are shown in Fig. 9. The structural stability of MLG was determined from the intensity ratios of the D and G peaks $\left(\mathrm{I}_{\mathrm{D}} / \mathrm{I}_{\mathrm{G}}\right)[41,42]$.

The spectrum of the initial powder mixture of $\mathrm{SiC} / 3 \mathrm{wt} \%$ MLG contains relatively low intensity bands of $\alpha-\mathrm{SiC}$ in the $700-1000 \mathrm{~cm}^{-1}$ range, centered at about 788 and $965 \mathrm{~cm}^{-1}$, corresponding to the transverse-optical (TO) and longitudinal optical (LO) modes, respectively. The low intensity of the $\mathrm{SiC}$ bands is the result of the coverage of these larger particles by the graphene flakes, masking partially the signal of $\mathrm{SiC}$. The spectrum comprises the three typical bands of MLG, as well. The G-band at $1567 \mathrm{~cm}^{-1}$ is representing the stretching vibrations, the Dband at $1345 \mathrm{~cm}^{-1}$ is the characteristic signal of defects in the graphene structure, while the 2Dband at $2693 \mathrm{~cm}^{-1}$ shows the second order feature of the latter one. Comparison of the Raman spectra of the initial and the sintered samples revealed that the sintered sample exhibited very intensive SiC-related peaks and less intensive graphene peaks, the intensity of the SiC signals increased and that of the graphene decreased significantly. These changes are in line with the large difference in the area ratio of the two phases, shown in the cross-section TEM depicted in Fig. 8, where the Raman spectra were acquired from.

In the range of $538-1083 \mathrm{~cm}^{-1}$ new peaks appeared, what were related to the $\mathrm{B}_{4} \mathrm{C}$ phase formed during the SPS treatment. Analysis of the intensity ratio of the $D$ and $G$ bands of the 
starting powder and the SPS sintered composite, very large difference was evaluated: while the $\mathrm{I}_{\mathrm{D}} / \mathrm{I}_{\mathrm{G}}$ of the initial MLG was $\sim 0.21$, it increased to $\sim 0.81$ after SPS. It referred to structural changes, namely increase of disorder in MLG on sintering. Similar results have been published for other graphene-containing composites earlier [39, 43].

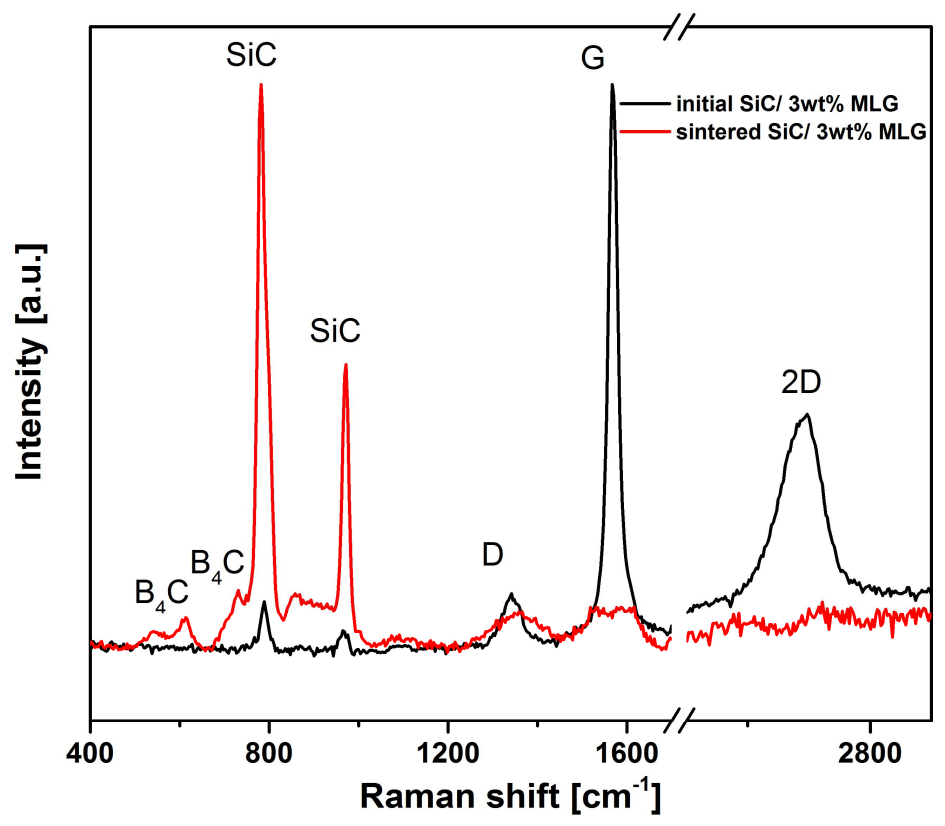

Fig. 9. Comparison of Raman spectra at $532 \mathrm{~nm}$ for starting SiC/3wt\% MLG powder (black line) and SPS sintered $\mathrm{SiC} / 3 \mathrm{wt} \% \mathrm{MLG}$ sintered at $1850^{\circ} \mathrm{C}$ (red line)

The increased intensity of the $\mathrm{D}$ band in sintered composites could be interpreted considering different factors: $(A)$ at the applied sintering temperature and pressure the originally perfect graphene plates are significantly distorted and $(B)$ micro-discharges could likely be developed between the loosely adjacent graphene flakes and they may lead to an imperfect intergrowth of MLG grains. The defected interphases increase the relative intensity of the D band, and thus, the $\mathrm{D} / \mathrm{G}$ ratio. The TEM micrograph in Fig. 8. supports this mechanism, showing an incomplete graphitization in the agglomerated MLG, that one can observe on the multi-layered graphene sheets of $\sim 15-20 \mathrm{~nm}$ thickness within the graphite grains as a result of imperfect intergrowth.

\subsection{Mechanical properties}

The hardness (HV) and the Young's modulus (E) of the sintered samples were measured by instrumented indentation test. The fracture toughness $\left(\mathrm{K}_{\mathrm{IC}}\right)$ was determined from the indentation data and the formed crack lengths according to the Niihara equation [33]. The effects of MLG content on the Vickers micro-hardness and Young's modulus is shown in Fig. 10. 

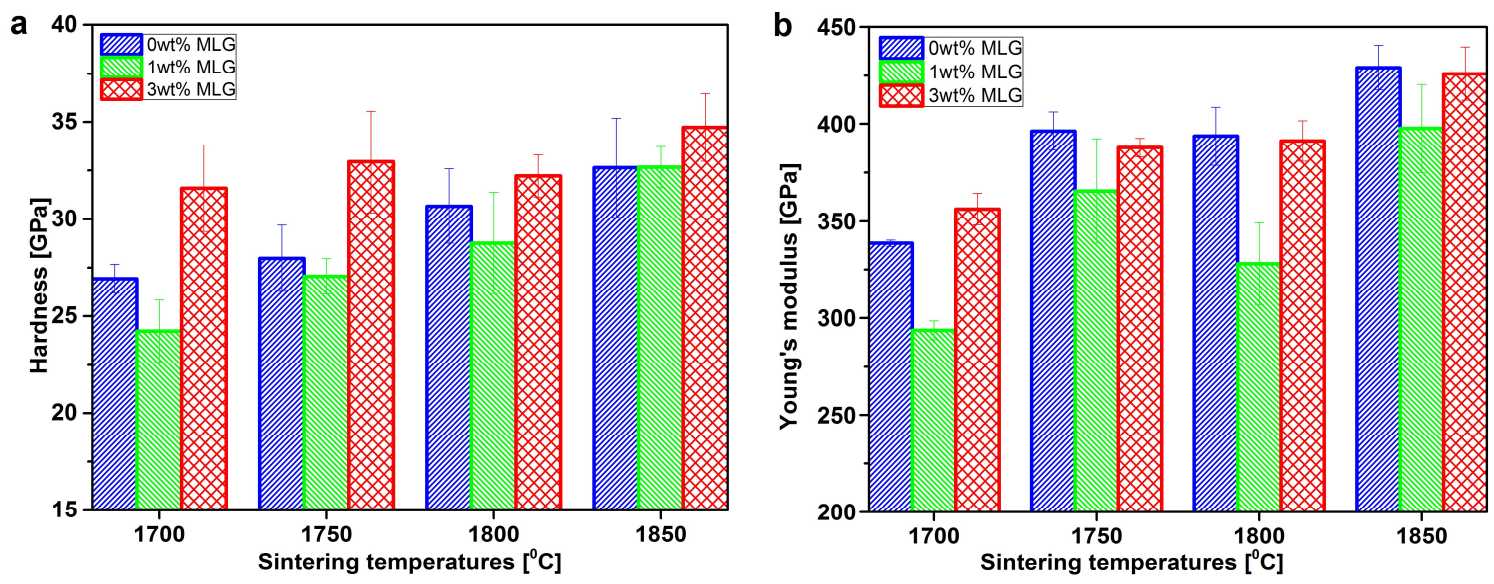

Fig. 10. The Vickers hardness (a) and Young's modulus (b) obtained at various sintering temperatures

As it was expected, the hardness improved both with the sintering temperature and the MLG content. The smallest micro-hardness of $26.9 \pm 1.6 \mathrm{GPa}$ was obtained for samples with $1 \mathrm{wt} \%$ MLG content, sintered at $1700^{\circ} \mathrm{C}$, which is explained by the low relative density of $90.8 \%$ (Fig. 1.). However, as it can be seen in Fig. 10.a the hardness of composites strongly depended on the sintering temperature in all samples. Vickers hardness also increased with the sintering temperature. Our results refer to the close correlation of micro-hardness with the relative density of sintered ceramics. The $\mathrm{SiC} / 3 \mathrm{wt} \%$ MLG composite exhibited the highest Vickers hardness even at the lowest temperature of $1700^{\circ} \mathrm{C}$. In this case, the hardness was $31.6 \pm 2.2 \mathrm{GPa}$, which was higher by $17 \%$ than that of sample without graphene.

According to the literature, MLG addition may induce porosity in the matrix and thus, reduces the hardness $[14,27]$. Our results did not support these observations: in samples sintered at $1750^{\circ} \mathrm{C}$ and above, no pore formation was observed either in the SEM, or in the TEM micrographs. The nearly theoretical densities of samples sintered above $1750^{\circ} \mathrm{C}$ indicated negligible pore formation even in case of MLG addition. Besides the dense microstructure, the intergranular $\mathrm{B}_{4} \mathrm{C}$ could also contribute to the improvement of micro-hardness.

As it can be seen in Fig. 10.b the Young's modulus of the composites changed similarly to the micro-hardness and the relative density against the sintering temperature. It refers to the correlation of particular mechanical properties with the relative densities. Similar phenomenon was found by Tonello [38] between the Young's modulus and the porosity of sintered ceramics. The Young's modulus of the MLG-free reference samples and that of those reinforced with 3 $\mathrm{wt} \%$ MLG were fairly close to each other at higher sintering temperatures. Greater differences occurred only at composites sintered at or below $1750^{\circ} \mathrm{C}$. In the case of $1 \mathrm{wt} \% \mathrm{MLG} / \mathrm{SiC}$ composites the Young's modulus showed significantly lower values, however, as it can be seen in the Fig. 10.b, the $\mathrm{E}$ is increased with the rising sintering temperatures, too. 


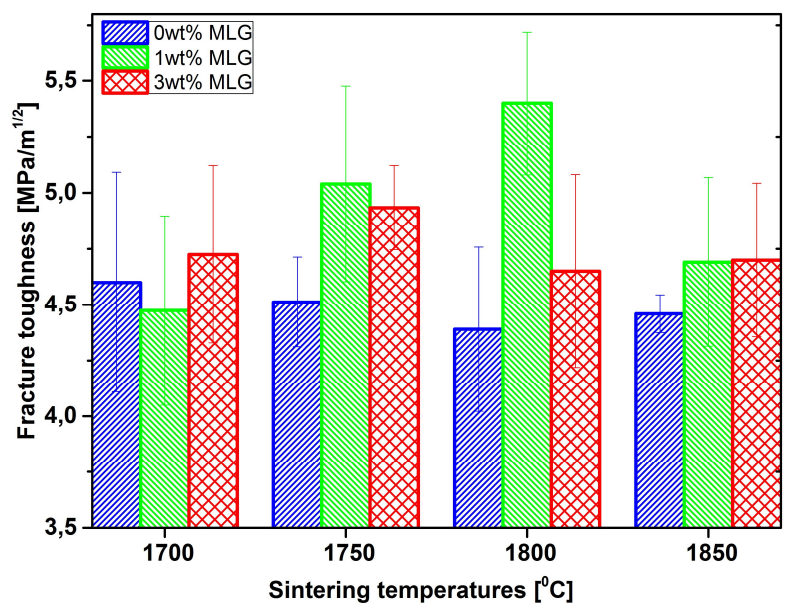

Fig. 11. Fractures toughness $\left(\mathrm{K}_{\mathrm{IC}}\right)$ obtained at different sintering temperatures

The effects of MLG content on the fracture toughness is shown in Fig. 11. It was found that MLG addition improved the fracture toughness of the composites comparing with the reference samples. While the micro-hardness and Young's modulus correlated rather well with the sintering temperature and the relative densities, the connection of fracture toughness with these parameters seems to be more complex (Fig. 11.): (A) composites with $3 \mathrm{wt} \%$ MLG content exhibited higher $\mathrm{K}_{\mathrm{IC}}$ values as compared to MLG-free reference samples; nevertheless, for both sets of sintered ceramics, $\mathrm{K}_{\mathrm{IC}}$ hardly changed against the sintering temperature; $(B)$ the highest fracture toughness was detected at composite of $1 \mathrm{wt} \%$ MLG content; $(C)$ the $\mathrm{K}_{\mathrm{IC}}$ values of the $1 \mathrm{wt} \%$ MLG sample increased by $20 \%$ up to $1800^{\circ} \mathrm{C}\left(5.4 \pm 0.3 \mathrm{MPa} \cdot \mathrm{m}^{1 / 2}\right)$, although it dropped back at $1850^{\circ} \mathrm{C}$. Observation $(A)$ can be explained by the increased ratio of rod- like $4 \mathrm{H}-\mathrm{SiC}$ crystals in the microstructure and the formation of intergranular $\mathrm{B}_{4} \mathrm{C}$ that consumes more crack extension energy than SiC and MLG and could change the fracture mode of the composite. Finding $(B)$ was attributed to better separation and more uniform distribution of graphene platelets at lower MLG content. Belmonte et al. [29] also observed a maximum- type run of the fracture toughness vs. MLG content curve. However, they attained the maximum fracture toughness at $10 \mathrm{vol} \%$ GNP content. The highest value at $1 \mathrm{wt} \%$ MLG content in our test suggests a more effective and uniform distribution of graphene platelets in the matrix. Statement $(C)$ ascribed mainly to the toughening effects of pulling-out and crack bridging mechanism of MLG.

\section{Conclusions}

MLG reinforced $\mathrm{SiC}$ nanocomposites were produced by solid-state sintering in the presence of $3 \mathrm{wt} \% \mathrm{~B}$ using SPS at $1700^{\circ} \mathrm{C}, 1750^{\circ} \mathrm{C}, 1800^{\circ} \mathrm{C}$ and $1850^{\circ} \mathrm{C}$, respectively. Polymorphic phase transformations and structural changes were detected in the sintered bodies with increasing temperature. XRD analysis indicated partial $6 \mathrm{H} \rightarrow 4 \mathrm{H}-\mathrm{SiC}$ phase transformation. SEM micrographs revealed elongated $\mathrm{SiC}$ grains, which could improve the fracture toughness of composites. Intergranular $\mathrm{B}_{4} \mathrm{C}$ phases strongly bonded to $\mathrm{SiC}$ grains were also formed according 
to TEM investigations. Some structural changes in the MLG were detected, as well. The relative density of specimens increased both with increasing sintering temperature and MLG addition. The MLG-containing samples had almost full relative density soon at $1750^{\circ} \mathrm{C}$, due to the improvement of heat transfer conditions within ceramic bodies during SPS. The Vickers hardness of sintered ceramics significantly improved when $3 \mathrm{wt} \% \mathrm{MLG}$ was added to the SiC-B powder. In this case, the micro-hardness became larger by $17 \%$ even at $1700^{\circ} \mathrm{C}$ as compared to the reference sample not containing MLG. In all samples the hardness increased against the sintering temperature. It was attributed to the increase of relative densities on the one hand, and to the formation of hard intergranular $\mathrm{B}_{4} \mathrm{C}$ phase, on the other. The sintered composite with $1 \mathrm{wt} \%$ MLG content exhibited the lowest Young's modulus. However, for all samples the Young's modulus increased with the sintering temperature. In contrast, sample loaded by $1 \mathrm{wt} \%$ MLG had the highest fracture toughness, which was higher by $20 \%$ as compared to the reference sample. This increase can presumably be reasoned by the complex effects of graphene toughening mechanisms including MLG pull-out and crack bridging and by the formation of elongated $4 \mathrm{H}-$ SiC grains.

\section{Acknowledgement}

The authors would like to thank Dr Jenő Gubicza (Department of Materials Physics, Eötvös Loránd University) for the opportunity to perform the mechanical tests. The authors are also grateful to Gábor Babos (Institute of Materials and Environmental Chemistry, Research Center for Natural Sciences, Hungarian Academy of Sciences) and Andrea Fenyvesi-Jakab (Institute for Technical Physics and Materials Science, Centre for Energy Research, Hungarian Academy of Sciences) for the preparation of samples to TEM measurements. 


\section{References}

[1] S. E. Saddow, A. Agarwal, Advances in Silicon carbide processing and applications, Silicon carbide Overview, Artech House, Inc. Boston, (2004) pp. 1-23

[2] S. P. Lee, Y. S. Shin, D. S. Bae, B. H. Min, J. S. Park, A. Kohyama, Fabrication of liquid phase sintered SiC materials and their characterization, Fusion Eng. Des. 81 (2006) 963-967

[3] A. Maitre, Vande Put, J.P. Laval, S. Valette, G. Trolliard, Role of boron on the Spark Plasma Sintering of an alpha-SiC powder, J. Eur. Ceram. Soc., 28 (2008) 1881-1890

[4] A. Can, M. Herrmann, D. S. McLachlan, I. Sigalas, J. Adler, Densification of liquid phase sintered silicon carbide, J. Eur. Ceram. Soc., 26 (2006) 1707-1713

[5] Y. Shinoda, Y. Suzuki, K. Yoshidac, TEM analysis of nanocrystalline SiC ceramics sintered by SPS using $\mathrm{Al}_{2} \mathrm{O}_{3}-\mathrm{TiO}_{2}$ additive, J. of Asian Ceram. Soc., 1 (2013) 267-273

[6] H. Tanaka, Silicon carbide powder and sintered materials, J. Ceram. Soc. J., 119 (2011) 218233.

[7] L. Stobierski, A. Gubernat, Sintering of silicon carbide, Effect of boron, Ceram. Int., 29 (2003) 355-361

[8] N. Song, H. Zhang, H. Liu, J. Fang, Effects of SiC whiskers on the mechanical properties and microstructure of $\mathrm{SiC}$ ceramics by reactive sintering, Ceram. Int., 43 (2017) 6786-6790

[9] M. Wilhelm M. Kornfeld, W. Wruss, Development of SiC-Si Composites with Fine-grained SiC Microstructures, J. Eur. Ceram. Soc., 19 (1999) 2155- 2163

[10] N.P. Padture, In situ-toughened silicon carbide J. Am. Ceram. Soc., 77 (1994), pp. 519-523

[11] A. Kovalcíková, J. Dusza, P. Sajgalík, Thermal shock resistance and fracture toughness of liquid-phase-sintered SiC-based ceramics, J. Eur. Ceram. Soc., 29 (2009) 2387-2394

[12] T. Kuilla, S. Bhadra, D. H. Yao, N. H. Kim, S. Bose, J. H. Lee, Recent advances in graphene based polymer composites, Prog. Polym. Sci., 35 (2010) 1350-1375

[13] M. Rashad, F. Pan , J. Zhang, M. Asif, Use of high energy ball milling to study the role of graphene nanoplatelets and carbon nanotubes reinforced magnesium alloy, J. Alloys Compd. 646 (2015) 223-232

[14] J. Liu, H. Yan, M. J. Reece, K. Jiang, Toughening of zirconia/alumina composites by the addition of graphene platelets, J. Eur. Ceram. Soc., 32 (2012) 4185-4193

[15] H. Porwal, P. Tatarko, S. Grasso., J. Khaliq., I Dlouhy, M. J. Reece, Graphene reinforced alumina nano-composites, Carbon, 64 (2013) 359-369

[16] Y. Fan, L. Wang, J. Lib, J. Lia, S. Sun, F. Chen, L. Chen, W. Jiang, Preparation and electrical properties of graphene nanosheet $/ \mathrm{Al}_{2} \mathrm{O}_{3}$ composites, Carbon 48 (2010) 1743-1749

[17] Q. Li, Y. Zhanga, H. Gong, H. Sun, T. Li, X. Guo, S. Ai, Effects of graphene on the thermal conductivity of pressureless-sintered SiC ceramics, Ceram. Int., 41 (2015) 13547-13552

[18] B. Roman-Manso, Y. Chevillotte, M. I. Osendi, M. Belmonte, P. Miranzo, Thermal conductivity of silicon carbide composites with highly oriented graphene nanoplatelets, J. Eur. Ceram. Soc., 36 (2016) 16 3987-3993

[19] H. Porwal, P. Tatarko, R. Saggar, S. Grasso, M. Kumar Mani, I. Dlouhý, J. Dusza, M. J. Reece, Tribological properties of silica-graphene nano-platelet composites, Ceram. Int., 40 (2014) 12067-12074 
[20] R. J. Young, I. A. Kinloch, L. Gong, K. S. Novoselov, The mechanics of graphene nanocomposites: A review, Compos. Sci. Technol., 72 (2012) 1459-1476

[21] F. Chen, D. Jina, K. Tyeba, B. Wanga, Y.-H. Hanb, S. Kimb, J. M. Schoenungd, Q. Shena, L. Zhanga, Field assisted sintering of graphene reinforced zirconia ceramics, Ceram. Int., 41 (2015) 6113-6116

[22] C. Ramirez, M. I. Osendi, Toughening in ceramics containing graphene fillers, Ceram. Int., 40 (2014) 11187-11192.

[23] L. S. Walker, V. R. Marotto, M. A. Rafiee, N. Koratkar, E. L. Corral, Toughening in graphene ceramic composites, ACS Nano, 5 (2011) 3182-3190

[24] M. Michálková, M. Kašiarová, P. Tatarko, J. Dusza, P. Šajgalík, Effect of homogenization treatment on the fracture behavior of silicon nitride/graphene nanoplatelets composites, J. Eur. Ceram. Soc., 36 (2016) 3051-3057

[25] Sz. Klébert, Cs. Balázsi, K. Balázsi, E. Bódis, P. Fazekas, A. M. Keszler, J. Szépvölgyi, Z. Károly, Spark plasma sintering of graphene reinforced hydroxyapatite, Ceram. Int., 41 (2015) 3647-3652

[26] H. Porwal, S. Grasso, M. J. Reecel, Review of graphene-ceramic matrix composites, Adv. Appl. Ceram., 112 (2013), 443-454

[27] E. Bódis, O. Tapasztó, Z. Károly, P. Fazekas, Sz. Klébert, A M. Keszler, K. Balázsi, J. Szépvölgyi, Spark plasma sintering of $\mathrm{Si}_{3} \mathrm{~N}_{4} /$ multilayer graphene composites, Open Chem., 13 (2015) 484-489

[28] P. Miranzo C. Ramírez, B. Roman-Manso, L. Garzón, H.R. Gutiérrez, M. Terrones, C. Ocal, M. I. Osendi, M. Belmonte, In situ processing of electrically conducting graphene/SiC nanocomposites, J. Eur. Ceram. Soc., 33 (2013) 1665-1674

[29] M. Belmonte, A. Nistal, P. Boutbien, B. Román-Manso, M. I. Osendi, P. Miranzo, Toughened and strengthened silicon carbide ceramics by adding graphene-based fillers, Scripta Mater., 113 (2016) 127-130

[30] Q. Li , Y. Zhang, H. Gong , H. Sun ,W. Li , L. Ma Y. Zhang, Enhanced fracture toughness of pressureless-sintered SiC ceramics by addition of graphene, J. Mat. Sci \& Tech., 32 (2016) 633-638

[31] P. Kun, F. Wéber, Cs. Balázsi, Preparation and examination of multilayer graphene nanosheets by exfoliation of graphite in high efficient attritor mill, Cent. Eur. J. Chem., 9 (2011) 47-51

[32] W. C. Oliver, G. M. Pharr, An improved technique for determining hardness and elastic modulus using load and displacement sensing indentation experiments, J. Mater. Res., 7 (1992) 1564-1583

[33] K. Niihara, R. Morena, D. P. Hasselman, Evaluation of $K_{I C}$ of brittle solids by the indentation method with low crack-to-indentation ratios, J. Mater. Sci. Lett., 1 (1982) 13-16

[34] F. Sergejev, M. Antonov, Comparative study on indentation fracture toughness measurements of cemented carbides, Proc. Estonian Acad. Sci. Eng., 12 (2006) 388-398

[35] E. Rudnayov, J. Dusza, M. Kupkov, Comparison of fracture toughness measuring methods applied on silicon nitride ceramics, J. Phys. IV, 3 (1993) 1273-1276 
[36] C. Ramirez, M. I. Osendi, Toughening in ceramics containing graphene fillers, Ceram. Int., 40 (2014) 11187-11192

[37] A. Nieto, D. Lahiri, A. Agarwal, Graphene nanoplatelets reinforced tantalum carbide consolidated by spark plasma sintering, Mater. Sci. Eng. A 582 (2013) 338-346

[38] K. Pereira dos Santos Tonello, E. Padovano, C. Badini, S. Biamino, M. Pavese, P. Fino, Fabrication and characterization of laminated $\mathrm{SiC}$ composites reinforced with graphene nanoplatelets, Mat. Sci. \& Eng. A 659 (2016) 158-164

[39] G. Topates, L. Mammitzsch, U. Petasch, J. Adler, F. Kara, H. Mandal, Microstructurepermeability relation of porous $\beta$-Si3N4 ceramics, J. Eur. Ceram. Soc., 33 (2013) 1545-1551

[40] A. Kovalcíková, J. Sedlácek, Z. Lencés, R. Bystricky, J. Dusza, P. Sajgalík, Oxidation resistance of $\mathrm{SiC}$ ceramics prepared by different proceessing routes, J. Eur. Ceram. Soc., 36 (2016) 3783-3793

[41] A. C. Ferrari, J. C. Meyer, V. Scardaci, C. Casiraghi, M. Lazzeri, F. Mauri, S. Piscanec, D. Jiang, K. S. Novoselov, S. Roth, A. K. Geim Raman Spectrum of Graphene and Graphene Layers, Phys. Rev. Lett., 97 (2006) 187401

[42] S. Drewniak, T. Pustelny, I. Pasternak, A. Krajewska, G. Konieczny, Study of Morphology of Graphene using Atomic Force Microscopy and Raman Spectroscopy, Phot. Lett. Poland 6(4) (2014) $120-122$

[43] F. Inam, T. Vo, B. R. Bhat, Structural stability studies of graphene in sintered ceramic nanocomposites Ceram. Int., 40 (2014) 16227-16233 